\title{
Development of a Scale to Measure Histrionic Traits According to the Hierarchical Taxonomy of Psychopathology
}

\author{
Lucas de Francisco Carvalho*, 1 \\ Orcid.org/0000-0002-3274-9724 \\ Catarina P. Sette ${ }^{1}$ \\ Orcid.org/0000-0001-6285-0826
}

Bárbara Letícia Ferrari ${ }^{1}$

Orcid.org/0000-0001-9127-9972

${ }^{1}$ Universidade São Francisco, Campinas, SP, Brasil

\begin{abstract}
The aim of this study was to develop a version of the Dimensional Clinical Personality Inventory 2 (IDCP-2) focusing on the Histrionic Personality Disorder (HPD) traits according to the Hierarchical Taxonomy of Psychopathology (HiTOP) model, and to verify its psychometric properties. The method was divided into two stages. The first was related to the revision procedures of the IDCP-2 based on the HiTOP, focusing on the assessment of features typical of HPD. The second aimed to verify the psychometric properties of the new version of the IDCP-2 (i.e., IDCP-HPD) in a convenience sample $(N=208)$, mainly composed of women, with data collection carried out online. The IDCP-HPD was administered with the Personality Inventory for DSM-5 (PID-5) and Five-Factor Histrionic Inventory (FFHI) factors. Of the 16 initial traits provided by the HiTOP, 8 were selected as relevant for the HPD and 17 items were selected to compose the new factors. The 4 factor solution found through exploratory structural equation modeling, the correlations with the external measures and the effects found in the between-group comparisons suggest the psychometric adequacy of the IDCP-HPD. The findings of this study should be interpreted as initial evidence for the IDCP-HPD, indicating the practicality of the test.
\end{abstract}

Keywords: Personality disorders, cluster B, diagnosis.

\section{Desenvolvimento de Uma Escala para Avaliar Traços do Transtorno da Personalidade Histriônico de Acordo com o Hierarchical Taxonomy of Psychopathology}

\section{Resumo}

O objetivo deste estudo foi desenvolver uma versão do Inventário Dimensional Clínico da Personalidade 2 (IDCP-2) focada nos traços do transtorno da personalidade histriônico (TPH) de acordo com o modelo Hierarchical Taxonomy of Psychopathology (HiTOP), e verificar suas propriedades psicométricas. O

* Mailing address: Universidade São Francisco, Programa de Pós-graduação em Psicologia, Rua Waldemar César da Silveira, 105, Campinas-SP, Brazil 13045-510. Phone: (55 19) 3779-3300. E-mail: lucas@labape. com.br

Grant funding: Coordenação de Aperfeiçoamento de Pessoal de Nível Superior (CAPES) 
método foi dividido em dois estágios. O primeiro para revisão do IDCP-2 de acordo com o HiTOP, focando nos traços típicos do TPH. O segundo objetivou verificar as propriedades da nova versão do IDCP-2 (i.e., IDCP-HPD) em uma amostra por conveniência ( $N=208)$, coletada via online. O IDCPHPD foi aplicado junto a fatores do Personality Inventory for DSM-5 (PID-5) e Five-Factor Histrionic Inventory (FFHI). Dos 16 traços iniciais baseados no HiTOP, 8 foram selecionados para o TPH e 17 itens foram selecionados para os novos fatores. A solução com 4 fatores observada via exploratory structural equation modeling, as correlações com medidas externas e os efeitos das comparações entre grupos indicam a adequação psicométrica do IDCP-HPD. Os achados devem ser interpretados como evidências iniciais para o IDCP-HPD, indicando a praticidade do teste.

Palavras-chave: Transtornos da personalidade, cluster B, diagnóstico.

\section{Desarrollo de Una Escala para Medir los Rasgos de los Trastornos Histriónicos de la Personalidad de Acuerdo con la Taxonomía Jerárquica de la Psicopatologia}

\section{Resumen}

El objetivo de este estudio fue desarrollar una versión del Inventario Dimensional Clínico del Personalidad 2 (IDCP-2) que se centra en los rasgos del desorden histriónico de la personalidad (HPD) según el modelo de Taxonomía Jerárquica de la Psicopatología (HiTOP) y verificar sus propiedades psicométricas. El método se dividió en dos. Primero se relacionó con los procedimientos de revisión del IDCP-2 basados en el HiTOP, centrándose en la evaluación de las características típicas de HPD. El segundo verificou las propiedades psicométricas de la nueva versión del IDCP-2 (IDCP-HPD) en una muestra de conveniencia $(N=208)$, con la recopilación de datos en línea. El IDCP-HPD se administró con el Personality Inventory for DSM-5 (PID-5) y Five-Factor Histrionic Inventory (FFHI). De los 16 rasgos iniciales del HiTOP, 8 fueron seleccionados para el HPD y 17 ítens fueron seleccionados para componer los nuevos factores. La solución de 4 factores encontrada en modelo exploratorio de ecuaciones estructurales, las correlaciones y los efectos en las comparaciones entre grupos sugieren la adecuación psicométrica del IDCP-HPD. Los hallazgos de este estudio deben interpretarse como evidencia inicial para el IDCP-HPD, que indica la practicidad de la prueba.

Palabras clave: Desorden de personalidade, cluster B, diagnóstico.

Evidence suggests that the symptoms that compose psychopathologies, specifically personality disorders (PDs), are best represented on a continuum rather than as restrictive categories, as not everyone presents the same levels in the various pathological traits (Forbes et al., 2017; Hopwood et al., 2018; Krueger \& Markon, 2014; Samuel \& Widiger, 2008; Wright et al., 2013). From this perspective, a dimensional model for the classification of psychopathologies was proposed, the Hierarchical Taxonomy of Psychopathology (HiTOP; Kotov et al., 2017), organizing disorders into levels, called Superspectra, Spectra, Subfactors, Syndromes/Disorders, Components, and Symptoms. Personality disorders are contemplated in the Syndromes/ Disorders level, encompassing disorders from section 2 of the DSM-5 (American Psychiatry Association [APA], 2013), excluding obsessivecompulsive PD and dependent PD. In this study, the focus was on the histrionic PD (HPD).

The HiTOP authors highlight that no assessment tool has been developed so far that includes all the symptoms and traits of the model, however, tests assessing some of these have been presented (Kotov et al., 2017). Although the majority of these tests are not available in developing countries, such as Brazil, locally developed measures can be used, as is the case of the Dimensional Clinical Personality Inventory 
2 (IDCP-2; Carvalho \& Primi, in press). The aim of this study was to develop a new version of the IDCP-2, focused on the HPD according to the HiTOP.

\section{Theoretical Background}

The HPD is conceptualized by the DSM-5 (APA, 2013) as a prevailing pattern of attention seeking and exaggerated emotionality. The core traits are the need to be the center of attention, excessively dramatic behaviors, rapid and superficial shifts of emotions, as well as tending to be suggestible, with the emotional expression being shallow and lacking in details. Other relevant traits are seductive behavior, excessive sociability (Millon, 2016), and lack of attention to details (Novais, Araujo, \& Godinho, 2015). Some traits are shared with other PDs, mainly with the narcissistic PD (NPD), such as the need for attention and recognition, emotional lability, and seductive behavior (Furnham, 2014; Gore, Tomiatti, \& Widiger, 2011; Samuel, Lynam, Widiger, \& Ball, 2012; Zimmerman, 2012). Those diagnosed with HPD also tend to present very high levels of extroversion, excitement seeking, and gregariousness, as well as high levels of impulsivity and openness to experience (Furnham, 2014). The expectation for HPD occurrence in community samples is about 1.8\% (APA, 2013). In an epidemiologic study in Brazil, in the São Paulo Metropolitan Area, a frequency of $2.7 \%$ of cases of Cluster B PDs was observed (Santana et al., 2018).

Recently, a nosological model including PDs, the Hierarchical Taxonomy of Psychopathology (HiTOP; Kotov et al., 2017), was proposed. The HiTOP is composed of six strata, with a general factor of psychopathology at the highest level, followed by broad domains (i.e., somatoform, internalizing, externalizing (disinhibited and antagonistic), thought disorder, and detachment). These broad domains, or spectra, are divided into subfactors (e.g., fear and antisocial behavior). The subfactors are composed of disorders (e.g., borderline PD and antisocial PD), which leads to two more specific strata, components (or traits) and symptoms.
Is this model, the HPD traits are located in two spectra, Antagonistic externalizing and Detachment (inverse pole). For instance, traits from the Antagonistic externalizing spectrum typical of HPD are attention seeking, grandiosity, and flirtatiousness; and from the Detachment spectrum (inverse pole), intimacy avoidance, withdrawal, and interpersonal passivity.

The traits in the HiTOP can be assessed by specific tests, identified in the literature by the authors (Kotov et al., 2017). Some of these tools are adapted for Brazil, such as the Personality Inventory for DSM-5 (PID-5; Krueger, Derringer, Markon, Watson, \& Skodol, 2012), however, the majority have not been adapted (e.g., Computerized Adaptive Test of Personality Disorder - CAT-PD; Personality Assessment Inventory - PAI; Minnesota Multiphasic Personality Inventory-2 - MMPI-2). In the Brazilian context, the Dimensional Clinical Personality Inventory 2 (IDCP-2; Carvalho \& Primi, in press) is the only self-report inventory developed in the country for the assessment of PD traits, in consonance with section 3 of the DSM-5 (e.g., Carvalho, 2018; Carvalho \& Sette, 2017), and with the spectra level of the HiTOP (Pianowski, Carvalho, \& Miguel, 2019), in addition to other models (i.e., the dimensions listed by Clark, 1990; dimensions of the Shedler-Westen Assessment Procedure - SWAP; Shedler \& Westen, 2004; and the pathological characteristics reported in Theodore Millon's theory; Millon, 2011).

Although none of the dimensions of the IDCP-2 sufficiently represent all the HPD traits, there is evidence that the Attention seeking dimension is closely related to the typical traits of HPD (Abela, Carvalho, Cho, \& Yazigi, 2015; Carvalho \& Primi, 2015, 2016). Among these traits, the seduction and manipulation behaviors, exaggeration of the expression of feelings, need to be the center of attention, and the belief in being able to establish intimate relationships easily and quickly can be emphasized.

This study is part of a wider research project, the main aim of which is to update the IDCP-2 according to the HiTOP. The aim of this study was to develop a version of the IDCP-2 focused on the HPD traits and based on the HiTOP (i.e., 
IDCP Histrionic Personality Disorder Scale; IDCP-HPD), as well as to verify its psychometric properties.

\section{Method}

Considering the aim of this study, the method was divided into two stages. The first (Stage I) referred to the procedures for the revision of the IDCP-2 based on the HiTOP, focusing on the evaluation of typical HPD traits; the second (Stage II) aimed to verify the psychometric properties of the new version of the IDCP-2 for HPD traits, the IDCP-HPD, in a community sample.

\section{Stage 1 - Procedures for Revision of the IDCP-2 based on the HiTOP}

Firstly, the spectra of the HiTOP that encompass the HPD were verified, with the selection and definition of the traits relevant to this disorder. It should be highlighted that a deliberate attempt was made to maintain as many traits as possible, aiming for the representativeness of typical HPD traits. Based on this, a search for definitions was conducted in the literature, mainly according to the measurement tests mentioned in Table 1 of Kotov et al. (2017), such as the Personality Inventory for DSM5 (PID-5; Krueger et al., 2012); Personality Assessment Inventory (PAI; Morey, 2015); Five Factor model of Personality Disorder (FFMPD; Trull, 2012); Computerized Adaptive Test of Personality Disorder static form (CAT-PD-SF; Simms et al., 2011); and Minnesota Multiphasic Personality Inventory (MMPI-2; Butcher et al., 1989). Next, the IDCP-2 factors representing the target traits were selected, starting from the selected HiTOP traits related to HPD and making use of the previously established definitions, the IDCP-2 factors that appropriately cover these traits were indicated. In this procedure, gaps in the IDCP-2 assessment of the HiTOP HDP traits were identified. Traits not covered by the IDCP-2 were operationalized by the authors (i.e., one $\mathrm{PhD}$. expert in personality disorders, one psychology doctoral candidate, and one psychologist with a Master's degree). In other words, items were developed to represent all the unrepresented or not well-represented traits from the HiTOP. The development of the selfreport items was conducted independently by the authors. The authors, by consensus, selected the most adequate items from the conceptual point of view, based on content and semantic issues. Specifically, the clarity, consistency and redundancy of the items were verified, the latter, regarding non-repetition of the characteristics already evaluated by the IDCP-2. After these procedures, the first version of the IDCP-HPD was defined according to empirical psychometric verification.

Step 2 - Verification of the

Psychometric Properties of the IDCP-HPD

\section{Participants}

Participants included 208 subjects, aged between 18 and 66 years $(M=32.22 ; S D=9.79)$, 170 females $(82.2 \%)$, with the majority being Caucasian (75.5\%). Most of the participants were single $(54.8 \%)$, had incomplete higher education $(28.4 \%)$ and complete postgraduate education (27.9\%). Regarding their history of psychiatric/psychological treatment, $27.8 \%$ of the subjects reported undergoing or having already undergone psychiatric treatment, 53.8\% reported undergoing or having undergone psychotherapeutic counselling, and $18.7 \%$ had made use of psychotropic medication. Specifically in relation to mental disorders and symptoms, some participants reported past suicidal ideation $(40.8 \%)$, suicide attempts (13.9\%) and some of the participants $(22.1 \%)$ reported having received a psychiatric diagnosis.

The expectation for HPD occurrence in community samples is about $1.8 \%$ (APA, 2013). In an epidemiological study in Brazil, in the São Paulo Metropolitan Area, a frequency of 2.7\% of cases of PDs from Cluster B was observed (Santana et al., 2018). Therefore, for the present study, people with elevations in the typical traits of HPD were expected, although there should only be a small number of people with a HPD diagnosis. 


\section{Instruments}

\section{Dimensional Clinical Personality}

Inventory 2 (IDCP-2; Carvalho \& Primi, in press). The IDCP-2 is a reviewed version of the IDCP (Carvalho \& Primi, 2015), covering the pathological characteristics reported in the theoretical proposal of Theodore Millon (2011), the diagnostic categories of the DSMIV- TR Axis II (APA, 2003), and section 2 of the DSM-5 (2013), as well as the traits reported in section 3 of the DSM- 5 and the Personality Inventory for DSM 5 (PID-5; Krueger et al., 2012), the dimensions assessed by the ShedlerWesten Assessment Procedure (SWAP; Shedler \& Westen, 2004) and the dimensions listed by Anna Clark (1990), which provide the basis for the Schedule for Nonadaptive and Adaptive Personality (SNAP). The IDCP-2 is a self-report instrument for assessing pathological personality traits, composed of 206 items distributed in 12 dimensions, with a 4-point Likert-type response scale $(1=$ "has nothing to do with me" and $4=$ "has a lot to do with me"). For this study, according to the traits assessed by each IDCP-2 factor, specific factors were selected: Deceitfulness (Inconsequence dimension; Carvalho, 2018), Need for recognition and Superiority (Grandiosity dimension; Carvalho, Sette, \& Ferrari, 2016); Seduction and manipulation, Emotional intensity and Attention seeking (Attention Seeking dimension, Carvalho, Sette, Capitão, \& Primi, 2014). Previous studies presented validity evidence and reliability adequacy for these factors (Carvalho, 2018; Carvalho et al., 2014; Carvalho et al., 2016). The 45 items selected in Stage 1 of this study were also administered. These items represent the Interpersonal activity, Intimacy seeking, and Flirtation traits.

Five Factor Histrionic Inventory (FFHI; Tomiatti, Gore, Lynam, Miller, \& Widiger, 2012). The FFHI was design to assess the HPD. It is comprised of 260 items on a 4-point Likerttype response scale, where 1 stands for "has nothing to do with me" and 4 for "has everything to do with me". For this study, only one factor was selected, Flirtatiousness $(\alpha=0.72)$. A total of 10 items were used. Studies have shown satisfactory psychometric properties for the FFHI (Tomiatti et al., 2012). With approval from the author of the original test, the translation and cultural adaptation of the test items were performed for use in the present study.

Personality Inventory for DSM-5 (PID5; Krueger et al., 2012). This is a self-report inventory to assess pathological personality traits and was developed to measure criterion $\mathrm{B}$ of this hybrid model in section 3 of the DSM-5 (APA, 2013). It includes 220 items on a 4-point Likert-type scale, where 1 stands for "has nothing to do with me" and 4 for "has a lot to do with me". The PID-5 is represented by 25 facets, grouped into 5 dimensions (i.e., Negative Affect, Detachment, Antagonism, Disinhibition, and Psychoticism). For this study, some facets were selected: Intimacy avoidance $(\alpha=0.80)$, Grandiosity $(\alpha=0.77)$, Deceitfulness ( $\alpha=0.82$ ) and Manipulativeness $(\alpha=0.86)$. A total of 27 items were used. Studies have shown satisfactory psychometric properties for the PID5 (Al-Dajani, Gralnick, \& Bagby, 2016; Krueger et al., 2012). The Brazilian version, translated and adapted for Brazil by Primi et al. (2013), was used.

\section{Procedures}

This study was conducted with the approval of the Brazilian Research Ethics Committee (CAAE: 21992113.1.0000.5514) and the participants signed a consent form. Online data collection was carried out using the Google Forms platform, inviting volunteers through e-mails and social networking sites (e.g., WhatsApp, Facebook). The protocol comprised a form to attest the voluntary participation, followed by a demographic data questionnaire and the instruments. The volunteers took approximately 25 minutes to respond to the survey, composed of 82 self-report items.

According to the aims of this study, in stage 1 the relevant traits for the HPD were selected from the HiTOP, which are presented in Table 1. From this selection, new items were developed, and new factors established, producing the version to be administered in stage 2 of the IDCP-HPD. In stage 2, the psychometric pro- 
perties were verified through exploratory structural equation modeling (E-SEM), using parallel analysis as the indicator of the number of factors. In the measurement model, only the items composing each factor were specified, with the other parts being freely estimated. See Table 1 for the number of items developed for each factor. Internal consistency and intracorrelations were calculated as indicators of reliability. Correlations were performed between the IDCPHPD factors and the respective external measures according to Table 1. The bootstrap twosample t-test was also performed, creating two groups from the total sample: the healthy group $(n=72)$, composed of people that reported never having undergone psychotherapy or psychiatric treatment, never having had suicidal thoughts and never having made a suicide attempt, and the pathological group $(n=38)$, composed of people that reported having a psychiatric diagnosis and participating in psychiatric treatment. The psych package (Revelle, 2018) of the R software version 3.4.0 was used for the parallel analysis calculation, MPlus software version 7 for the E-SEM, and SPSS software version 21 for the reliability, correlations and t-test with bootstrap. The $p$-values $<.05$ were considered significant.

\section{Results}

\section{Stage 1 - IDCP-2 Revision Procedures according to Pathological Traits from the Spectra of the HiTOP Model}

In Table 1 the spectra from the HiTOP related to the HPD are presented, as well as the respective traits, and the traits typical of HPD. Trait selection was performed independently by the researchers of the study. Consensus was reached when disagreements emerged. The table also contains the IDCP-2 factors, the measures developed and the correspondent external measures representing the HPD traits from the HiTOP.

Table 1

Selected Traits, IDCP-2 Factors, Developed Measures, and External Measures Based on HPD Spectra from HiTOP

\begin{tabular}{ccccc}
\hline Spectra & Traits & Selected traits & $\begin{array}{c}\text { IDCP-2 factors and } \\
\text { developed measures }\end{array}$ & $\begin{array}{c}\text { Respective external } \\
\text { measures }\end{array}$ \\
\hline & Attention Seeking & Attention Seeking & Attention seeking & - \\
Callousness & Deceitfulness & Deceitfulness & Deceitfulness & (PID-5) \\
& Grandiosity & Grandiosity & $\begin{array}{c}\text { Need for recognition Superiority } \\
\text { Seduction and manipulation }\end{array}$ & $\begin{array}{c}\text { Deceitfulness (PID-5) } \\
\text { Grandiosity (PID-5) }\end{array}$ \\
& Manipulativeness & Manipulativeness & - & Manipulativeness \\
(PID-5)
\end{tabular}

Note. New factors are bolded; in brackets are the number of items developed to the new factor and the final number of items. 
From the 16 traits (Attention seeking appears in the two spectra), 8 were selected as relevant to HPD. A total of 35 new items were developed in order to represent the three traits considered relevant. From them, 17 were selected to compose the final version of the three new factors. Selection was based on clarity, redundancy and content, as well as verifying whether the exclusion of any item would decrease the internal consistency of the new factors, which was not observed.

\section{Stage 2 - Verification of the Psychometric Properties of the IDCP-HPD}

The psychometric properties (i.e., validity based on internal structure and external criteria, as well as internal consistency reliability) of the item set were investigated, starting from the parallel analysis for polychoric variables, determining the maximum number of factors for the test. Up to four factors were obtained, with significant eigenvalues not randomly established. Next, exploratory structural equation modeling (E-SEM; Marsh, Morin, Parker, \& Kaur, 2014) was performed, forcing two to four factor solutions using the Geomin oblique rotation (typically chosen considering intercorrelation between personality traits) and the Maximum Likelihood Robust (MLR) extraction method, considered a robust method suitable for polychoric variables ( $\mathrm{Li}, 2016$ ). The suitability of the Matrix correlations for the analysis was indicated through the fit indices from the E-SEM.

The indices for the models were evaluated, with the four factor structure identified as the best fit model. For the models with fewer factors, only poor fit indices were observed. However, the interpretability of the three models (i.e., 2, 3, and 4 factors) was verified. The model with four factors showed the best interpretability. Based on this, the solution composed of four factors was chosen. The fit indices obtained were $\mathrm{X}^{2} /$ $d f=1.12($ good $) ;$ RMSEA $=0.02($ good $) ;$ CFI $=$ 0.99 (good); TLI $=0.99$ (good); and $\mathrm{SMR}=0.01$ (good), based on the index criterion of Hooper, Coughlan, and Mullen (2008). Table 2 shows the factor loadings, mean of the correlations between the measures composing the factor; and internal consistency (Cronbach's $\alpha$ ) for the measures and factors. The measures considered to compose each factor are shown in bold.

Table 2

Factor Loadings of IDCP-2 Measures and Developed Measures

\begin{tabular}{cccccc}
\hline Measures & $\alpha$ (items) & IM & Super. & Grand. & AS \\
\hline Superiority & $.91(5)$ & .48 & $\mathbf{. 7 5}$ & $\mathbf{. 6 1}$ & -.15 \\
Deceitfulness & $.81(6)$ & .91 & .17 & .47 & .06 \\
Attention Seeking & $.75(4)$ & .12 & -.34 & .23 & $\mathbf{. 5 8}$ \\
Need for Recognition & $.90(4)$ & .46 & .34 & $\mathbf{. 9 4}$ & .07 \\
Seduction and Manipulation & $.81(3)$ &. $\mathbf{7 5}$ & .38 & .33 & .20 \\
Emotional Intensity & $.86(3)$ & .34 & -.03 & $.54^{*}$ & $\mathbf{. 5 1}$ \\
Interpersonal activity & $.83(5)$ & .12 & .37 & .29 & $\mathbf{. 4 0}$ \\
Intimacy Seeking & $.81(5)$ & .12 & -.13 & .00 &. $\mathbf{7 6}$ \\
Flirtation $^{\mathrm{a}}$ & $.83(7)$ &. $\mathbf{5 7}$ & .05 & .18 & .44 \\
$\mathrm{r}_{\text {average }}$ & & .53 & -- & .64 & .32 \\
$\boldsymbol{\alpha}$ & .77 & .71 & -- & .77 & .64 \\
\hline
\end{tabular}

Note. * This measure was excluded from the Grandiosity factor because it decreased the reliability and the mean of correlation between the variables. In bold higher factor loadings, indicating measures composing each factor. (items) $=$ number of items composing each measure. IM = Interpersonal Manipulation; Super. = Superiority; Grand. = Grandiosity; AS = Attention Seeking.

adeveloped measures; 
Almost all the measures showed internal consistency higher than .80 , with the exception of Attention Seeking. Reliability for the total score covering the nine measures administered was .77. The mean correlations of measures composing each factor suggest higher consistency for the Interpersonal Manipulation and Grandiosity factors, with lower indices observed for the
Attention Seeking factor. The Superiority factor was named according to the only measure that loaded more expressively, with the other factors being composed of two to four measures. Table 3 presents the correlations between the IDCP2 measures and three ${ }^{1}$ of the four factors found with the PID-5, FFHI and FFAVA measures administered.

Table 3

Correlations between IDCP-2 Measures, New Measures, and factors with PID-5, FFHI, and FFAVA

\begin{tabular}{|c|c|c|c|c|c|c|}
\hline \multirow{2}{*}{ Measures } & \multicolumn{6}{|c|}{ External measures } \\
\hline & AS & Grand. & Mani. & Dec. & IA & Flir. \\
\hline Attention Seeking & $.82^{* *}$ & .11 & .04 & .09 & .03 & $.30^{* *}$ \\
\hline Need for Recognition & $.26^{* *}$ & $.35^{* *}$ & $.51^{* *}$ & $.48^{* *}$ & $.16^{*}$ & $.26^{* *}$ \\
\hline Seduction and Manipulation & .07 & $.40^{* *}$ & $.72^{* *}$ & $.51^{* *}$ & $.16^{*}$ & $.35^{* *}$ \\
\hline Deceitfulness & $.17^{*}$ & $.32^{* *}$ & $.74^{* *}$ & $.68^{* *}$ & $.19^{* *}$ & $.42^{* *}$ \\
\hline Superiority & -.01 & $.34^{* *}$ & $.61^{* *}$ & $.46^{* *}$ & .10 & .09 \\
\hline Emotional Intensity & $.44^{* *}$ & $.22^{* *}$ & $.34^{* *}$ & $.35^{* *}$ & $.26^{* *}$ & $.38^{* *}$ \\
\hline Interpersonal activity & .11 & $.25^{* *}$ & .2 te $1^{* *}$ & $.17^{*}$ & .01 & .10 \\
\hline Intimacy Seeking & $.31^{* *}$ & $.17^{*}$ & -.01 & .02 & -.01 & $.31^{* *}$ \\
\hline Flirtation & $.23^{* *}$ & $.21^{* *}$ & $.38^{* *}$ & $.33^{* *}$ & .11 & $.62^{* * *}$ \\
\hline Interpersonal Manipulation (higher order) & $.19^{* *}$ & $.37^{* *}$ & $.73^{* *}$ & $.61^{* *}$ & $.18^{* *}$ & $.56^{* *}$ \\
\hline Grandiosity (higher order) & $.14^{*}$ & $.38^{* *}$ & $.61^{* *}$ & $.52^{* *}$ & $.14^{*}$ & $.19^{* *}$ \\
\hline Attention Seeking (higher order) & $.60^{* *}$ & $.27^{* *}$ & $.22^{* *}$ & $.24^{* *}$ & .12 & $.40^{* *}$ \\
\hline IDCP-HPD total score & $.44 * *$ & $.45 * *$ & $.66^{* *}$ & $.58 * *$ & $.19 * *$ & $.51 * *$ \\
\hline
\end{tabular}

Note. $\mathrm{AS}=$ Attention Seeking; Grand. = Grandiosity; Mani. = Manipulativeness; Dec. $=$ Deceitfulness; IA $=$ Intimacy Avoidance; Flir. = Flirtatious. In bold the correlations between IDCP-2 factors and the respective external measure according to Table $1 .{ }^{* *}$ Correlation is significant at the 0.01 level; $*$ Correlation is significant at the 0.05 level.

The expected correlations were observed, although in some cases larger effect sizes were found with other measures. Factors from the IDCP-2 (Attention seeking, Seduction and manipulation, and Emotional intensity) showed higher correlations with the expected external measures; Deceitfulness (IDCP-2) presented the highest correlation with the factor from the PID5 of the same name; Need for recognition and Superiority showed significant correlations with the expected measures, however, the highest correlation was not with them. Regarding the three new factors, Flirtation and Intimacy seeking (inverted correlation) showed the highest correlations with the expected measures, however, the negative correlation expected for Interpersonal activity was not observed. As expected, the Interpersonal Manipulation higher order factor presented the highest correlations with the Manipulativeness, Deceitfulness, and

1 We did not include the Grandiosity factor as it resembles the Grandiosity measure from the IDCP-2. 
Flirtatious factors; the Grandiosity higher order factor with Manipulativeness, Deceitfulness, and Grandiosity; and the Attention Seeking higher order factor with the Attention Seeking and Flirtatious factors. Furthermore, the total score correlated with all the external measures, showing correlations from .44 to .66 in almost all cases, except for Intimacy Avoidance, in which the correlation was lower. Table 4 presents the results of the comparison between the healthy and pathological groups.

Table 4

Comparison between Health $(n=72)$ and Pathological $(n=38)$ Groups in Factors from IDCP-HPD

\begin{tabular}{|c|c|c|c|c|c|c|c|c|}
\hline \multirow{2}{*}{ Factors } & \multirow{2}{*}{ Groups } & \multirow{2}{*}{ Mean } & \multirow{2}{*}{$S D$} & \multicolumn{2}{|c|}{$\mathrm{BCa} 95 \% \mathrm{CI}$} & \multirow{2}{*}{$t$} & \multirow{2}{*}{$d f$} & \multirow{2}{*}{$p(d)$} \\
\hline & & & & Lower & Upper & & & \\
\hline \multirow{2}{*}{$\begin{array}{l}\text { Seduction and } \\
\text { manipulation }\end{array}$} & + & 2.04 & 0.525 & 1.93 & 2.16 & \multirow{2}{*}{-0.518} & \multirow{2}{*}{55.507} & \multirow{2}{*}{$.59(0.11)$} \\
\hline & - & 2.11 & 0.772 & 1.87 & 2.36 & & & \\
\hline \multirow{2}{*}{ Emotional intensity } & + & 2.16 & 0.669 & 2 & 2.31 & \multirow{2}{*}{-3.893} & \multirow{2}{*}{53.391} & \multirow{2}{*}{$\begin{array}{l}0.001 \\
(0.89)\end{array}$} \\
\hline & - & 2.89 & 1.046 & 2.54 & 3.2 & & & \\
\hline \multirow{2}{*}{ Attention seeking } & + & 1.88 & 0.42 & 1.79 & 1.98 & \multirow{2}{*}{-5.266} & \multirow{2}{*}{49.031} & \multirow{2}{*}{$.001(1.27)$} \\
\hline & - & 2.59 & 0.765 & 2.32 & 2.86 & & & \\
\hline \multirow{2}{*}{ Need for recognition } & + & 2.37 & 1.028 & 2.13 & 2.61 & \multirow{2}{*}{0.852} & \multirow{2}{*}{85.062} & \multirow{2}{*}{$.4(0.16)$} \\
\hline & - & 2.21 & 0.894 & 1.94 & 2.48 & & & \\
\hline \multirow{2}{*}{ Superiority } & + & 2.48 & 1.125 & 2.21 & 2.75 & \multirow{2}{*}{3.794} & \multirow{2}{*}{100.751} & \multirow{2}{*}{$.34(0.68)$} \\
\hline & - & 1.79 & 0.77 & 1.55 & 2.01 & & & \\
\hline \multirow{2}{*}{ Deceitfulness } & + & 1.74 & 0.522 & 1.62 & 1.86 & \multirow{2}{*}{0.107} & \multirow{2}{*}{55.716} & \multirow{2}{*}{$.93(0.03)$} \\
\hline & - & 1.72 & 0.764 & 1.51 & 1.96 & & & \\
\hline \multirow{2}{*}{ Intimacy Seeking } & + & 7.35 & 2.048 & 6.91 & 7.84 & \multirow{2}{*}{-6.134} & & \\
\hline & - & 10.35 & 2.619 & 9.5 & 11.18 & & 01.390 & (1.33) \\
\hline Interpersonal & + & 11.58 & 2.536 & 10.98 & 12.18 & 0767 & 60820 & $15(016)$ \\
\hline activity & - & 11.99 & 2.771 & 11.07 & 12.9 & & & (1) \\
\hline Flirtation & + & 1.8 & 0.499 & 1.69 & 1.92 & -223 & 52017 & $04(0-52)$ \\
\hline & - & 2.12 & 0.792 & 1.88 & 2.4 & & & \\
\hline IDCP-HPD & + & 2.09 & 0.42 & 1.99 & 2.19 & 2378 & 108 & $02(048)$ \\
\hline total score & - & 2.30 & 0.47 & 2.16 & 2.47 & $-2.5 / 0$ & 100 & $.05(0.40)$ \\
\hline
\end{tabular}

Note. $(+)$ health group; (-) pathological group. BCa 95\% CI = bias-corrected and accelerated (BCa) bootstrap interval; $d=$ Cohen's $d$.

Higher means for the pathological group were observed for almost all the factors, with the exception of Need for recognition, Superiority, and Deceitfulness. Considering the measures presenting higher means for the pathological group, Attention seeking, Emotional intensity and Intimacy seeking presented significant differences between groups. Regarding the other five measures, three of them showed significant differences, with higher means for the pathological group. In general, the observed effect sizes agreed with the significance level, being expressive only when significance was obtained. An exception to this was the Superiority factor, showing no significance, but an expressive effect size. 


\section{Discussion}

A version of the IDCP-2 (i.e., IDCP-HPD) focused on the assessment of the HPD traits according to the HITOP was developed. The psychometric properties of the IDCP-HPD were investigated in a community sample. Updating the test based on the HiTOP (Forbes et al., 2017; Kotov et al., 2017) helps to assure that the relevant traits are contemplated from a dimensional perspective. The development of tools to measure specific PDs is a practice already in motion (e.g., Tomiatti et al., 2012), facilitating the coverage of as many traits as possible for the pathological pattern, which supports a rigorous and effective assessment. In this study, the results suggest psychometric adequacy for the IDCP-HPD, corroborating the previous literature on HPD (APA, 2013; Forbes et al., 2017; Hopwood et al. 2018; Hopwood, Thomas, Markon, Wright, \& Krueger, 2012; Kotov, Krueger, \& Watson, 2018; Kotov et al., 2017; Krueger et al., 2012; Tomiatti et al., 2012), in which HPD is conceived from a dimensional perspective, with the diagnostic criteria described in the DSM-5 also taken into consideration.

Regarding the first stage of the study, the verification of the traits relevant for the HPD in the HiTOP suggested that some traits were not being covered in the IDCP-2. New items were created and grouped into factors, seeking to expand the coverage of the new version of the test. According to the antagonistic externalizing and detachment (inverse) spectra, three new factors were included, Flirtation, Intimacy seeking, and Interpersonal activity. Flirtation is related to the exaggerated need to flirt and feel sexually attractive to everyone; Intimacy seeking covers the tendency to give too much consideration to having intimacy with others and exhibiting explicit intimacy seeking behaviors; while Interpersonal activity includes the need to reveal the inner feelings and thoughts to others. These traits and the other traits covered by the factors of the IDCP-2 (i.e., Superiority, Deceitfulness, Attention Seeking, Need for
Recognition, Seduction and Manipulation, and Emotional Intensity) are considered relevant by the literature on HPD (Forbes et al., 2017; Hopwood et al., 2012; Kotov et al., 2018; Krueger et al., 2012; Tomiatti et al., 2012).

An internal structure for the nine traits of the IDCP-HPD was not hypothesized in advance. However, the expectation was to find trait groupings that reflect the HPD core modus operandi. The higher order structure composed of four factors was the one with the best statistical parameters and interpretability ratio. The four factors are related to the core symptoms of HPD (APA, 2013; Forbes et al., 2017; Hopwood et al., 2012; Krueger et al., 2012; Tomiatti et al., 2012). In general, the factors expressed the tendency to show superiority toward others and the need to be recognized by others (Superiority and Grandiosity); the need to manipulate and deceive others, the need to seduce people in order to be the center of the attentions (Interpersonal manipulation); and the exaggerated need to be the focus of attention as much as possible, expressing and verbalizing the inner feelings, and inappropriate attempts to establish intimate relationships. The first two factors are also related to the symptoms of the narcissistic personality disorder (NPD), which is understandable, as the NPD shares symptoms with the HPD (Hopwood et al., 2012; Samuel et al., 2012).

Reliability indicators were observed, specifically regarding internal consistency (i.e., Cronbach's alpha). Results for the nine factors that compose the IDCP-HPD indicate clinical adequacy considering the reliability (American Psychological Association, American Educational Research Association, \& National Council on Measurement in Education, 2014; Urbina, 2004). Similarly, the higher order factors and total score showed good reliability indices (Nunnally, 1978), although below .80, which must be considered by the professional using the IDCP-HPD.

Correlations between the IDCP-HPD factors and the external measures, in general, were in line with what was expected, as presented in Table 1, 
indicating validity evidence based on external variables. However, in some cases, higher correlations were observed with unexpected measures. The Need for recognition and Superiority factors showed higher correlations with the Manipulativeness factor (PID-5). It can be hypothesized that the beliefs of being able to manipulate others and affirming the use of this strategy as a means to achieve the aims (i.e., Manipulativeness - PID-5) is more common in people that see themselves as better than others (i.e., Superiority - IDCP-HPD) and that want to be recognized by others (i.e., Need for recognition-IDCP-HPD). Indeed, manipulation behaviors can be used as a means to sustain the beliefs about oneself and to maintain recognition from others. These relationships must be investigated in future studies. Furthermore, correlations with the Interpersonal activity and Intimacy seeking factors were not observed with the respective external measures. Possibly the correlations near to zero could be interpreted as an indication that people scoring high in these factors do not show a clear response pattern in the associated external measure (i.e., Intimacy Avoidance - PID-5). However, it should be noted that the correlations of these two IDCPHPD factors were positive and significant with the other measures that are similar to the HPD traits. The lack of relationship between the IDCP-HPD factors (Interpersonal activity and Intimacy seeking) and the specific factor of the PID-5 can be viewed as a tendency exhibited by people scoring high in the IDCP-HPD factors (i.e., a tendency to not typically express behaviors of the Intimacy Avoidance factor). These alternative hypotheses should be tested in future studies.

The group comparison helped to investigate the potential practical application of the IDCPHPD and its factors. In general, a tendency toward higher means for the pathological group in comparison to the healthy group was observed. The exceptions to this were not significant (i.e., the three factors where the healthy group showed higher means did not differentiate the groups). Considering the significant differences, the so called pathological group always presented higher means. The most expressive differences were observed for Attention seeking and Intimacy seeking, which are considered two core symptoms of the HPD (APA, 2013; Kotov et al., 2017; Krueger et al., 2012).

The findings of this study should be interpreted as initial evidence for the IDCPHPD. In general, the evidence corroborated the practicality of the test. Other studies must be carried out using clinical samples and, specifically, people diagnosed with HPD. Another limitation was that the community sample was not assessed in order to assure that the people included in the healthy group did not have HPD or another PD diagnosis. Studies with diagnostically accurate designs should be conducted, aiming to establish a cutoff point for the IDCP-HP.

\section{References}

Abela, R. K., Carvalho, L. D. F., Cho, S. J. M., \& Yazigi, L. (2015). Validity Evidences for the Dimensional Clinical Personality Inventory in Outpatient Psychiatric Sample. Paidéia (Ribeirão Preto), 25(61), 221-228. doi:10.1590/198243272561201510

Al-Dajani, N., Gralnick, T. M., \& Bagby, R. M. (2016). A psychometric review of the Personality Inventory for DSM-5 (PID-5): Current status and future directions. Journal of Personality Assessment, 98(1), 62-81. doi: 10.1080/00223891.2015.1107572

American Psychiatry Association. (2003). Diagnostic and Statistical Manual of Mental Disorders (4th Rev. Ed.). Washington, DC: Author.

American Psychiatry Association. (2013). Diagnostic and Statistical Manual of Mental Disorders 5. Washington, DC: Author.

American Psychological Association, American Educational Research Association, \& National Council on Measurement in Education. (2014). Standards for psychological and educational testing. New York: American Educational Research Association.

Butcher, J. N., Graham, J. R., Ben-Porath, Y. S., Tellegen, A., Dahlstrom, W. G., \& Kraemmer, 
B. (1989). The Minnesota Multiphasic Personality Inventory-2 (MMPI-2): Manual for administration and scoring. Minneapolis, $\mathrm{MN}$ : University of Minnesota Press.

Carvalho, L. F. (2018). Review study of the Impulsivity Dimension of the Dimensional Clinical Personality Inventory. Universitas Psychologica, 17(1), 1-11. doi: 10.11144/ Javeriana.upsy 17-1.rsid

Carvalho, L. F., \& Primi, R. (2015). Development and internal structure investigation of the Dimensional Clinical Personality Inventory. Psicologia: Reflexão e Crítica, 28(2), 322-330. doi: 10.1590/1678-7153.201528212

Carvalho, L. F., \& Primi, R. (2016). Prototype matching of personality disorders with the Dimensional Clinical Personality Inventory. Psicologia: Teoria e Pesquisa, 32(2). doi: 10.1590/0102-3772e322214

Carvalho, L. F., \& Primi, R. (in press). Manual técnico do Inventário Dimensional Clínico da Personalidade-2 (IDCP-2) [Technical Manual of the Dimensional Clinical Inventory of Personality-2 (IDCP-2)]. São Paulo, SP: Pearson.

Carvalho, L. F., \& Sette, C. P. (2017). Revision of the criticism avoidance dimension of the Dimensional Clinical Personality Inventory. Estudos de Psicologia (Campinas), 34(2), 219. 231. doi: 10.1590/1982-02752017000200004

Carvalho, L. F., Sette, C. P., Capitão, C. G., \& Primi, R. (2014). Propriedades psicométricas da versão revisada da dimensão Necessidade de Atenção do Inventário Dimensional Clínico da Personalidade [Psychometric Properties of the Revised Attention Seeking Dimension of the Inventário Dimensional Clínico da Personalidad]. Temas em Psicologia, 22(1), 147-160. doi: 10.9788/TP2014.1-12

Carvalho, L. F., Sette, C., \& Ferrari, B. L. (2016). Revision of the grandiosity dimension of the Dimensional Clinical Personality Inventory and verification of its psychometric properties. Trends in Psychiatry and Psychotherapy, 1, 1-9. doi: 10.1590/2237-6089-2015-0040

Clark, L. A. (1990). Toward a consensual set of symptom clusters for assessment of personality disorder. In J. N. Butcher \& C. D. Spielberger
(Eds.), Advances in personality assessment (pp. 243-266). Mahwah, NJ: Lawrence Erlbaum.

Forbes, M. K., Kotov, R., Ruggero, C. J., Watson, D., Zimmerman, M., \& Krueger, R. F. (2017). Delineating the joint hierarchical structure of clinical and personality disorders in an outpatient psychiatric sample, Comprehensive Psychiatry, 79, 19-30. doi: 10.1016/j. comppsych.2017.04.006

Furnham, A. (2014). A bright side, facet analysis of histrionic personality disorder: The relationship between the HDS colourful factor and the NEOPI-R facets in a large adult sample. The Journal of Social Psychology, 154, 527-536. doi: $10.1080 / 00224545.2014 .953026$

Gore, W. L., Tomiatti, M., \& Widiger, T. A. (2011). The home for histrionism. Personality and Mental Health, 5, 57-72. doi: 10.1002/pmh.151

Hooper, D., Coughlan, J., \& Mullen, M. R. (2008). Structural equation modelling: Guidelines for determining model fit. The Electronic Journal of Business Research Methods, 6(1), 53-60. Retrieved from https://arrow.dit.ie/cgi/viewcontent.cgi?referer $=\&$ httpsredir $=1 \&$ article $=1001 \&$ context=buschmanart

Hopwood, C. J., Kotov, R., Krueger, R. F., Watson, D., Widiger, T. A., Althoff, R. R., ...Bornovalova, M. A. (2018). The time has come for dimensional personality disorder diagnosis. Personality and Mental Health, 12(1), 82. doi: 10.1002/ pmh.1408

Hopwood, C. J., Thomas, K. M., Markon, K. E., Wright, A. G. C., \& Krueger, R. F. (2012). DSM5 Personality Traits and DSM-IV Personality Disorders. Journal of Abnormal Psychology, 121(2), 424-432. doi:10.1037/a0026656

Kotov, R., Krueger, R. F., \& Watson, D. (2018). A paradigm shift in psychiatric classification: The Hierarchical Taxonomy of Psychopathology (HiTOP). World Psychiatry, 17(1), 24-25. doi: 10.1002/wps.20478

Kotov, R., Krueger, R. F., Watson, D., Achenbach, T. M., Althoff, R. R., Bagby, R. M., ...Eaton, N. R. (2017). The Hierarchical Taxonomy of Psychopathology (HiTOP): A dimensional alternative to traditional nosologies. Journal of Abnormal Psychology, 126(4), 454. doi: 10.1037/abn0000258 
Krueger, R. F., Derringer, J., Markon, K. E., Watson, D., \& Skodol, A. E. (2012). Initial construction of a maladaptive personality trait model and inventory for DSM-5. Psychological Medicine, 8, 1-12. doi: 10.1017/S0033291711002674

Krueger, R. F., \& Markon, K. E. (2014). The role of the DSM-5 personality trait model in moving toward a quantitative and empirically based approach to classifying personality and psychopathology. Annual Review of Clinical Psychology, 10, 477-501. doi: 10.1146/annurevclinpsy-032813-153732

Li, C. G. (2016). Confirmatory factor analysis with ordinal data: Comparing robust maximum likelihood and diagonally weighted least squares. Behavior Research Methods, 48(3), 936-949. doi: 10.3758/s13428-015-0619-7

Marsh, H. W., Morin, A. J. S., Parker, P. D., \& Kaur, G. (2014). Exploratory Structural Equation Modeling: An integration of the best features of exploratory and confirmatory factor analysis. Annual Review of Clinical Psychology, 10, 85-110. doi: 10.1146/annurevclinpsy-032813-153700

Millon, T. (2011). Disorders of personality: Introducing a DSM/ICD spectrum from normal to abnormal (3rd Ed.). Hoboken, NJ: Wiley.

Millon, T. (2016). What is a personality disorder? Journal of Personality Disorders, 30(3), 289306.

Morey, L. C. (2015). Personality Assessment Inventory (PAI). The Encyclopedia of Clinical Psychology, 1(10). doi: 10.1002/ 9781118625392.wbecp284

Novais, F., Araújo, A., \& Godinho, P. (2015). Historical roots of histrionic personality disorder. Frontiers of Psychology, 25. doi: 10.3389/fpsyg.2015.01463

Nunnally, J. C. (1978). Psychometric Theory. NewYork: Mcgraw-Hill.

Pianowski, G., Carvalho, L. F., \& Miguel, F. K. (2019). Investigating the Spectra constellations of the Hierarchical Taxonomy of Psychopathology (HiTOP) model for personality disorders based on empirical data from a community sample. Brazilian Journal of Psychiatry, 41(2), 148-152. doi: 10.1590/1516-4446-2018-0015
Primi, R., Carvalho, L. F., Bandeira, D. R., Yazigi, L., Oliveira, S. E. S., \& Rossi, A. A. (2013). Versão brasileira do Personality Inventory for DSM-5 (PID-5). Unpublished technical material.

Revelle, W. (2018). Package 'psych'. Retrieved from https://cran.r-project.org/web/packages/psych/ psych.pdf

Samuel, D. B., Lynam, D. R., Widiger, T. A., \& Ball, S. A. (2012). An expert consensus approach to relating the proposed DSM-5 types and traits. Personality Disorders: Theory, Research, and Treatment, 3(1), 1-16. doi: 10.1037/a0023787

Samuel, D. B., \& Widiger, T. A. (2008). A metaanalytic review of the relationships between the Five-Factor Model and DSM-IV-TR Personality Disorders: A facet level analysis. Clinical Psychology Review, 28, 1326-1342. doi: 10.1016/j.cpr.2008.07.002

Santana, G., Coelho, B. M., Wang, Y. P., Chiavegatto, D. P. C., Filho, Viana, M. C., \& Andrade, L. H. S. G. (2018). The epidemiology of personality disorders in the Sao Paulo Megacity general population. PLoS ONE, 13(4), 1-20. doi: 10.1371/journal.pone.0195581

Simms, L. J., Goldberg, L. R., Roberts, J. E., Watson, D., Welte, J., \& Rottterman, J. H. (2011). Computerized Adaptive Assessment of Personality Disorder: Introducing the CAT-PD Project. Journal of Personality Assessment, 93(4), 380-389. doi: 10.1080/00223891.2011.577475

Shedler, J., \& Westen, D. (2004). Dimensions of personality pathology: An alternative to the five factor model. American Journal of Psychiatry, 161, 1743-1754. doi: 10.1176/appi. ajp.161.10.1743

Tomiatti, M., Gore, W. L., Lynam, D. R., Miller, J. D., \& Widiger, T. A. (2012). A five-factor measure of histrionic personality traits. In N. Gotsiridze Columbus (Ed.), Psychological assessment (pp. 113-138). Hauppage, NY: Nova Science.

Trull, T. J. (2012). The Five-Factor Model of Personality Disorder and DSM-5. Journal of Personality, 80(6), 1698-1720. doi: 10.1111/j.1467-6494.2012.00771.x

Urbina, S. (2004). Essentials of Psychological Testing. New Jersey, NJ: John Wiley \& Sons, Hoboken. 
Wright, A. G., Krueger, R. F., Hobbs, M. J., Markon, K. E., Eaton, N. R., \& Slade, T. (2013). The structure of psychopathology: Toward an expanded quantitative empirical model. Journal of Abnormal Psychology, 122, 281-294. doi: $10.1037 / \mathrm{a} 0030133$

Zimmerman, M. (2012). Is there adequate empirical justification for radically revising the personality disorders section for DSM-5?. Personality
Disorders: Theory, Research, and Treatment, 3(4), 444-457. doi: 10.1037/a0022108

Received: $14 / 09 / 2018$

$1^{a}$ revision: $22 / 01 / 2019$

Accepted: 23/01/2019 distribution, and reproduction in any medium, provided you give appropriate credit to the original author(s) and the source, provide a link to the Creative Commons license, and indicate if changes were made. 